\title{
Successful treatment of nonunion with teriparatide after failed ankle arthrodesis for Charcot arthropathy
}

\author{
K. Tamai $\cdot$ K. Takamatsu $\cdot$ K. Kazuki
}

Received: 19 March 2013 / Accepted: 2 April 2013 / Published online: 7 May 2013

(C) The Author(s) 2013. This article is published with open access at Springerlink.com

\begin{abstract}
We describe a case of successful treatment to nonunion after multiple arthrodesis operations for Charcot arthropathy with teriparatide. We describe the case of a 25 year-old woman with severe Type I diabetes mellitus that resulted in nonunion after multiple arthrodesis operations for Charcot arthropathy. The woman sustained a femoral shaft fracture for which she underwent surgery with intramedullary nail fixation. Immediately after surgery, an empiric course of teriparatide was initiated. Femoral shaft fracture healing was observed after 2 weeks, and the woman was able to walk 12 weeks after the surgery, at which point plain film and computed tomography images revealed complete union of the ankle.
\end{abstract}

Keywords Bone healing · Charcot arthropathy · Fracture · Nonunion · Teriparatide · Type I diabetes mellitus

\section{Introduction}

Arthrodesis is required for treating severe osteoarthritis accompanied by rheumatism, diabetes mellitus, chronic renal failure, and similar systemic diseases [1]. Nonunion of arthrodesis represents the most dramatic example of poor healing where the normal biologic healing process is insufficient for achieving complete union, and so surgical treatment of nonunion after arthrodesis is extremely challenging. Finding another way to treat nonunion after arthrodesis is therefore imperative. In terms of fracture healing, an accelerated effect of teriparatide has been reported in animal models as well as in several clinical studies [2-4]. Herein,

K. Tamai $(\bowtie) \cdot$ K. Takamatsu $\cdot$ K. Kazuki

Osaka City General Hospital, 2-13-22, Miyakojima hondori,

Miyakojimaku, Osaka, Japan

e-mail: tamaik1983_s58_04_22@yahoo.co.jp we report the case of a patient with ankle nonunion who underwent multiple unsuccessful arthrodesis operations, but achieved ankle union within 12 weeks with daily teriparatide administration.

\section{Case report}

A 25-year-old Japanese woman sustained a right femoral shaft fracture while climbing the stairs in May 2012 (Fig. 1a). She denied any abuse or accident such as falling down the stairs. She had a history of Type 1 diabetes mellitus, which was poorly controlled with insulin therapy (HbAlc, $16.7 \%$ ), and Charcot arthropathy of the ankle due to peripheral nerve disorder. An ankle arthrodesis had been performed at another clinic 15 months ago, but union was not achieved, and therefore, she underwent further surgery 12 months ago to fix her ankle. This treatment also failed resulting in nonunion, and so the woman was instructed to wear a patellar tendon-bearing brace for her ankle instability and pain (Fig. 2a, b). Her laboratory data, including serum levels of alkaline phosphate, parathyroid hormone, calcium, and phosphorus, were normal, but her level of 1.25 vitamin $\mathrm{D}_{3}$ was low, and her left femoral bone density was extremely low $\left(0.54 \mathrm{mg} / \mathrm{cm}^{2}\right)$ and 2.0 standard deviations below the normal value for her age (Table 1).

We treated the femoral shaft fracture with intramedullary nail fixation 29 days after the fracture occurred, because her chronic heart failure was too poor to allow for immediate

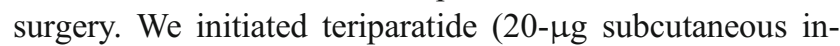
jection daily) and alfacalcidol (1- $\mu \mathrm{g}$ oral administration daily) immediately after surgery because of severe osteoporosis and in an attempt to accelerate healing of the femoral fracture. There was no immobilization of the femur, but a non-weight-bearing period of 4 weeks was implemented postoperatively. From 2 weeks after the initiation of 
Fig. 1 Radiographs of the femur. a 3D computed tomography images revealed an oblique fracture of the proximal shaft of the femur. b Plain film taken 2 weeks after surgery. Callus formation is visible around the fracture site. c Plain film taken 12 weeks after surgery. Large callus and consolidation are visible

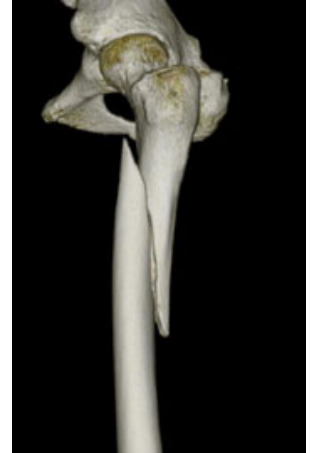

a

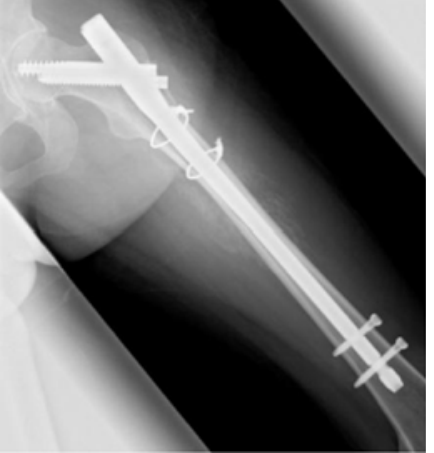

b

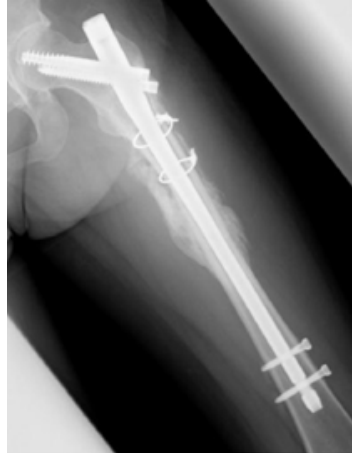

C

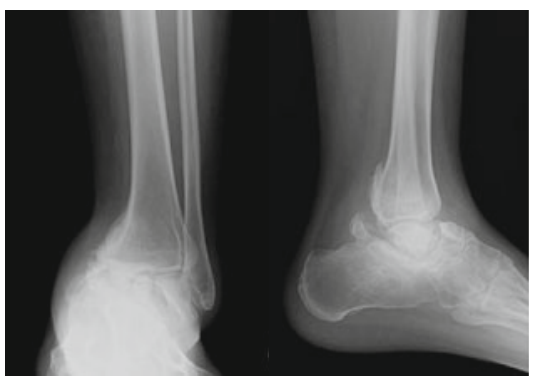

a
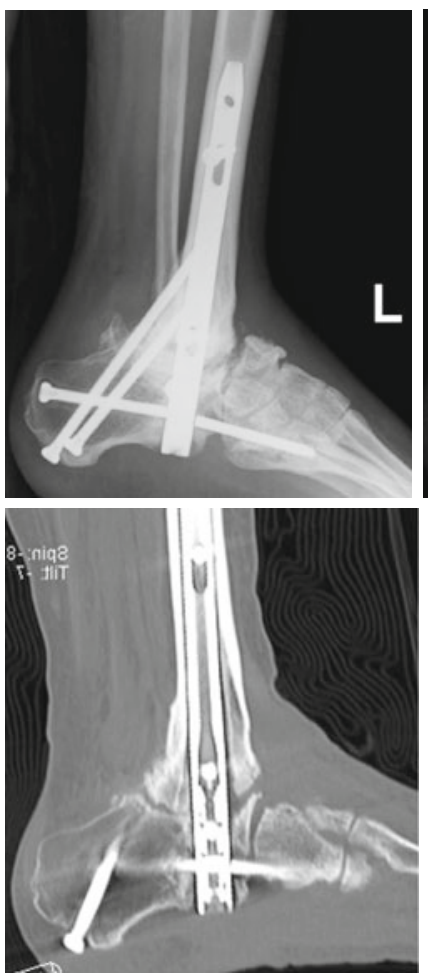

C

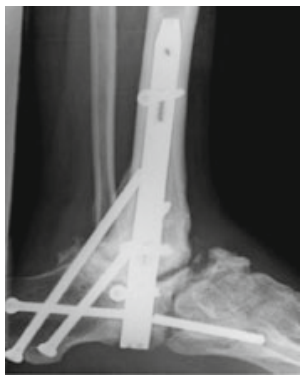

b
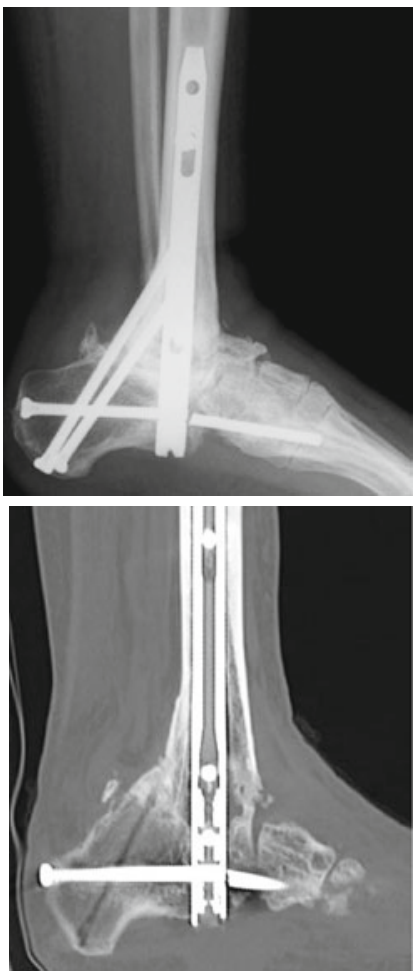

d
Fig. 2 Radiographs of the femur. a Plain film of the ankle with Charcot arthropathy before arthrodesis. b Plain film taken before teriparatide therapy was initiated showing atrophic nonunion of the ankle. c Plain film and sagittal CT images showing atrophic nonunion of the ankle after multiple arthrodesis operations. d Plain film and sagittal CT image taken after 12 weeks of teriparatide therapy showing complete healing of nonunion teriparatide therapy, plain radiography began showing callus formation on the femoral shaft fracture, and after 12 weeks, almost complete healing of the fractured bone was observed (Fig. 1b, c). We therefore allowed the woman to walk with full weight bearing. We noticed that her ankle pain disappeared once she had resumed walking. Radiography and computed tomography images revealed that union of the ankle had been achieved (Fig. 2c, d). No side effects attributable to the drug were observed during treatment, and her subsequent laboratory findings continued to be normal. At 6 months, the patient could walk without a brace and without any pain. Plain images taken at this time revealed complete healing of the fractured and nonunion sites.

Table 1 Laboratory data before and after teriparatide therapy

\begin{tabular}{lll}
\hline Reference & Pretreatment & After \\
Range, & & 3 months \\
Age-adjusted & & \\
\hline
\end{tabular}

\begin{tabular}{|c|c|c|c|}
\hline \multicolumn{4}{|l|}{ Protein $(\mathrm{g} / \mathrm{dl})$} \\
\hline Total & $6.7-8.3$ & 7.5 & 7.2 \\
\hline Albumin & $3.9-4.9$ & 3.1 & 3.5 \\
\hline ALP (IU/l) & $104-338$ & 281 & 1033 \\
\hline BUN (mg/dl) & $8.0-20.0$ & 21.7 & 19.1 \\
\hline Cre (mg/dl) & $0.36-1.06$ & 0.67 & 0.61 \\
\hline $\mathrm{Na}(\mathrm{mEq} / \mathrm{l})$ & $136-147$ & 136 & 134 \\
\hline $\mathrm{K}(\mathrm{mEq} / \mathrm{l})$ & $3.6-5.0$ & 4.6 & 4.9 \\
\hline $\mathrm{Cl}(\mathrm{mEq} / \mathrm{l})$ & 98-109 & 94 & 99 \\
\hline $\mathrm{Ca}(\mathrm{mEq} / \mathrm{l})$ & $8.8-10.2$ & 9.8 & 9.1 \\
\hline IP $(\mathrm{mEq} / \mathrm{l})$ & $2.5-4.5$ & 4.1 & 3.6 \\
\hline $\mathrm{Mg}(\mathrm{mEq} / \mathrm{l})$ & $1.8-2.4$ & 2 & 1.9 \\
\hline HbAlc (\%) & $4.6-6.2$ & 13.5 & 13.2 \\
\hline ACTH (pg/ml) & $7.2-63.3$ & 22.4 & \\
\hline Intact-PTH (pg/ml) & $10-65$ & 31 & \\
\hline Calcitonin (pg/ml) & $15-86$ & 35 & \\
\hline $1.25-$ Vit $\mathrm{D}_{3}(\mathrm{pg} / \mathrm{ml})$ & $20-60$ & 12 & 72 \\
\hline $\begin{array}{l}\text { NTx (nmol } \\
\text { BCE/mmol· Cr) }\end{array}$ & $8-70$ & 189 & 327 \\
\hline D-Pyr (nM/mM· Cr) & $2.8-7.6$ & 31.8 & 21.6 \\
\hline
\end{tabular}




\section{Discussion}

A major problem for patients with chronic diabetes mellitus is the development of peripheral neuropathy. Sensory loss leads to neuropathic ulceration, which is aggravated in the presence of foot and ankle deformities and causes excessive pressure on deformed areas, a condition that is known as Charcot arthropathy or diabetic ankle $[5,6]$. The main aims when treating Charcot arthropathy of the foot and ankle are to correct the deformity so that there is an appropriate distribution of pressure for healing and to prevent skin ulceration [7]. Surgical correction with internal fixation for Charcot arthropathy is associated with a high rate of complications and failure because of infection, bone softening, resorption, fragmentation, and breakage of the implant [8]. Our patient with severe Type I diabetes mellitus and Charcot arthropathy had undergone two failed operations. Ankle union was not achieved even after the second operation, and the patient sustained a femoral shaft fracture. Nonunion is a severe complication and has a negative impact on the quality of life; undoubtedly, a second intervention is therefore necessary, but it is not exempt from further risks and potential complications [9]. It is therefore important that some treatment that can resolve this problem should be undertaken, but a third surgery to fix nonunion is extremely difficult as the ankle needs to be stabilized and the bone needs to be strengthened.

Teriparatide (rhPTH 1-34) is an anabolic agent that is administered subcutaneously. Its anabolic effect is attributable to the stimulation of osteoblasts, which causes a net increase in both cancellous and cortical bone, thus improving the bone architecture [10,11]. Teriparatide has different effects on trabecular and cortical bone. Because of the high degree of remodeling and apoptosis of trabecular bone osteoblasts, teriparatide has a more profound effect on trabecular than on cortical bone, which has a lower degree of osteoblastic apoptosis [2]. Teriparatide also accelerates fracture healing by improving the biomechanical properties of the fracture callus and by increasing endochondral ossification and bone remodeling in animal models [3]. This effect has also been observed in several other clinical case reports [12-14]. In a more detailed prospective, randomized, double-blinded study in 102 postmenopausal women who underwent conservative treatment for distal radial fractures, Aspenberg [4] showed that the time to healing was shorter in the 20-mg teriparatide group than in the placebo group. These reports indicate that teriparatide accelerates healing of bone fractures.

Chintamaneni [1] described a case of nonunion in the body of the sternum of a 67-year-old man, and Rubery and Bukata [15] described a series of three cases of nonunion in type III odontoid fractures treated conservatively with external immobilization. These patients were all successfully treated with teriparatide after conservative therapy for nonunion. Alvaro [16] described a case of atrophic humeral shaft nonunion after intramedullary osteosynthesis with elastic nails, and Lee [17] described three cases of femoral nonunion after surgical fixation. Our patient was administered with teriparatide for 12 months after the diagnosis of nonunion. Union was obtained within 3 months at both the fracture and nonunion sites, and no adverse events occurred during or after treatment. To our knowledge, this is the first study to report successful treatment of nonunion after arthrodesis for Charcot arthropathy and accelerated fracture healing after teriparatide administration.

We report that teriparatide is a possible alternative to surgical intervention in difficult cases of nonunion. Welldesigned studies are warranted to verify the efficacy of this approach.

\section{Conflicts of interest None.}

Open Access This article is distributed under the terms of the Creative Commons Attribution Noncommercial License which permits any noncommercial use, distribution, and reproduction in any medium, provided the original author(s) and the source are credited.

\section{References}

1. Chintamaneni S, Finzel K, Gruber BL (2010) Successful treatment of sternal fracture nonunion with teriparatide. Osteoporos Int 21:1059-1063. doi:10.1007/s00198-009-1061-4

2. Jilka RL, O'Brien CA, Ali AA, Roberson PK, Weinstein RS, Manolagas SC (2009) Intermittent PTH stimulates periosteal bone formation by actions on post-mitotic preosteoblasts. Bone 44:275-286

3. Cipriano CA, Issack PS, Shindle L, Werner CM, Helfet DL, Lane JM (2009) Recent advances toward the clinical application of PTH (1-34) in fracture healing. HSS J 5:149-153. doi:10.1007/s11420-009-9109-8

4. Aspenberg P, Genant HK, Johansson T, Nino AJ, See K, Krohn K et al (2009) Teriparatide for acceleration of fracture repair in humans: a prospective, randomized, double-blind study of 102 postmenopausal women with distal radial fractures. J Bone Miner Res. doi:10.1359/jbmr.090731

5. Armstrong DG, Lavery LA, Harkless LB (1998) Who is at risk for diabetic foot ulceration? Clin Podiat Med Surg 15:11-19

6. Armstrong DG, Lavery LA (1998) Elevated peak plantar pressures in patients who have Charcot arthropathy. J Bone Joint Surg [Am] 80-A:365-369

7. Simon SR, Tejwani SG, Wilson DL, Santner TJ, Denniston NL (2000) Arthrodesis as an early alternative to non-operative management of Charcot arthropathy of the diabetic foot. J Bone Joint Surg $[\mathrm{Am}]$ 82-A:939-950

8. Bradley L (2007) Lamm, Paley D. Charcot neuroarthropathy of the foot and ankle in limb lengthening and reconstruction surgery. In: Rozbruch SR, Ilizarov S (eds) Limb lengthening and reconstruction surgery, vol 1. Informa Healthcare, London, pp 221-232

9. Axelrad T, Kakar S, Einhorn TH (2007) New technologies for the enhancement of skeletal repair. Injury 38S1:S49-S62. doi:10. 1016/j.injury.2007.02.010

10. Jiang Y, Zhao JJ, Mitlak BH, Wang O, Genant HK, Eriksen EF (2003) Recombinant human parathyroid hormone (1-34) [teriparatide] improves both cortical and cancellous bone structure. J Bone Miner Res 18:1932-1941. doi:10.1359/jbmr.2003.18.11.1932 
11. Rubin MR, Cosman F, Lindsay R, Bilezikian JP (2002) The anabolic effects of parathyroid hormone. Osteoporos Int 13:267277. doi:10.1007/s001980200026

12. Knecht TP (2004) Teriparatide and fracture healing in cortical bone. Endocr Pract 10:293

13. Puzas JE, Houck J, Bukata SV (2006) Accelerated fracture healing. J Am Acad Orthop Surg 14:S145-S151

14. Resmini G, Iolascon G (2007) 79-year-old post-menopausal woman with humerus fracture during teriparatide treatment. Aging Clin Exp Res 19:30-31
15. Rubery PT, Bukata SV (2010) Teriparatide may accelerate healing in delayed unions of type III odontoid fractures: a report of 3 cases. J Spinal Disord Tech 23:151-155. doi:10.1097/BSD.0b013e31819a8b7a

16. Oteo-Alvaro A, Moreno E (2010) Atrophic humeral shaft nonunion treated with teriparatide (rh PTH 1-34): a case report. J Shoulder Elbow Surg 19:e22-e28. doi:10.1016/j.jse.2010.05.005

17. Lee YK, Ha YC, Koo KH (2012) Teripatratide, a nonsurgical solution for femoral nonunion? A report of three cases. Ostheoporos Int 23:2897-2900. doi:10.1007/s00198-012-2172-x 